\title{
Aplikasi Kriptografi File Menggunakan Metode Blowfish dan Metode Base64 pada Dinas Kependudukan dan Pencatatan Sipil Kota Tangerang Selatan
}

\author{
Mujito \\ Program Studi Teknik Informatika, Fakultas \\ Teknologi Informasi, Universitas Budi Luhur \\ Jl. Raya Ciledug, Petukangan Utara, Kebayoran \\ Lama, Jakarta Selatan 12260 \\ Telp. (021) 5853753, Fax. (021) 5866369 \\ jitosalemba@gmail.com
}

\author{
Anugrah Bagus Susilo \\ Program Studi Teknik Informatika, Fakultas \\ Teknologi Informasi, Universitas Budi Luhur \\ Jl. Raya Ciledug, Petukangan Utara, Kebayoran \\ Lama, Jakarta Selatan 12260 \\ Telp. (021) 5853753, Fax. (021) 5866369 \\ anugrahbagussusilo@gmail.com
}

\begin{abstract}
Abstrak- Dinas kependudukan Dan Pencatatan Sipil Kota Tangerang Selatan adalah suatu instansi pemerintah yang menangani masalah kependudukan dan catatan sipil warga daerah Tangerang data-data pencatatan sipil meliputi data akte pernikahan, data akte kelahiran dan akte kematian. Data - data tersebut merupakan data yang bersifat rahasia jika data tersebut diketahui oleh orang yang tidak bertanggung jawab dapat disalah gunakan seperti data kartu tanda penduduk, jika jatuh ke tangan orang yang salah dan digunakan untuk melakukan tindakan kriminal seperti peminjaman uang dan lain sebagainya. Untuk mengatasi data tersebut diperlukan aplikasi yang dapat menyandikan atau mengenkripsi data tersebut, Dimana mekanismenya nanti data-data tersebut discan terlebih dahulu kemudian file image hasil scan akan di enkripsi menggunakan algoritma Blowfish terlebih dahulu baru kemudian di enkripsi lagi dengan algoritma Base64, aplikasi menggunakan bahasa pemprograman PHP. Data dapat diamankan dengan kriptografi algortima Blowfish dan Base64. Data tidak dapat dibuka oleh pihak yang tidak berhak yang tidak memiliki kunci untuk enkripsi dan dekripsi file.
\end{abstract}

Kata kunci-- Kriptografi, Blowfish, Base64, enkripsi, dekripsi

\section{PENDAHULUAN}

Dinas kependudukan Dan Pencatatan Sipil Kota Tangerang Selatan adalah suatu instansi pemerintah yang menangani masalah kependudukan dan catatan sipil warga daerah Tangerang data-data pencatatan sipil meliputi data akte pernikahan, data akte kelahiran dan akte kematian. Data - data tersebut merupakan data yang bersifat rahasia jika data tersebut diketahui oleh orang yang tidak bertanggung jawab dapat disalah gunakan seperti data kartu tanda penduduk, jika jatuh ke tangan orang yang salah dan digunakan untuk melakukan tindakan kriminal seperti peminjaman uang dan lain sebagainya. Dengan banyaknya data-data penting yang sering juga bersifat rahasia, maka pihak Dinas Kependudukan dan Pencatatan Sipil Kota Tangerang Selatan ingin membuat supaya data tersebut tidak dapat dibaca secara langsung, karena data tersebut di sandikan atau dienkripsi baru kemudian disimpan ke dalam basis data, dan jika ingin melihat data tersebut menjadi data asli maka perlu di dekrpsi yaitu mengubah data yang terenkripsi menjadi data asli.

Untuk lebih mengamankan proses enkripsi dan deskripsi, perlu dilakukan suatu mekanisme yang memberikan sedikit kemungkinan agar data asli tidak bisa dibongkar oleh penyerang. Sehingga penulis menggunakan 2 metode dalam melakukan proses enkripsi dan deskripsi, yaitu Blowfish dan Base64. Dengan menggunakan kombinasi antara kunci algoritma Blowfish dan Base64 diharapkan akan membuat pengamanan data memiliki tingkat keamanan yang lebih tinggi. Khususnya untuk data kependudukan dan catatan sipil sehingga data asli tersebut tidak dapat dibaca dan diterjemahkan oleh orang yang tidak bertanggung jawab.

Berdasarkan permasalahan tersebut penulis mengambil penelitian dengan judul "Aplikasi Kriptografi File Menggunakan Metode Blowfish Dan Metode Base64 Pada Dinas Kependudukan Dan Pencatatan Sipil Kota Tangerang Selatan”.

\section{A. Batasan Masalah}

Sesuai dengan judul skripsi ini, penulis memfokuskan masalah yang ada dan agar tidak menyimpang dari pokok bahasan maka penulis membuat batasan permasalahan yaitu:

- Pembuatan aplikasi menggunakan bahasa pemprograman PHP. 
- Proses enkripsi dan dekripsi hanya dilakukan untuk data kependudukan dan pencatatan sipil yaitu berupa file berbentuk image (.jpeg).

- Maksimal File yang dienkripsi sebesar 2 $\mathrm{Mb}$

\section{LANDASAN TEORI}

\section{A. Konsep Dasar Kriptografi}

Kriptografi berasal dari bahasa Yunani, crypto dan graphia. Crypto berarti secret (rahasia) dan graphia berarti writing (tulisan). Menurut terminologinya kriptografi adalah ilmu dan seni untuk menjaga keamanan pesan ketika dikirim dari suatu tempat ke tempat yang lain. (Ariyus, 2008) Kriptografi dapat pula diartikan sebagai ilmu atau seni untuk menjaga keamanan pesan. Ketika suatu pesan dikirim dari suatu tempat ke tempat lain, isi pesan tersebut mungkin dapat disadap oleh pihak lain yang tidak berhak untuk mengetahui isi pesan tersebut. Kriptografi diperlukan untuk menghindari pihak yang tidak berhak mengetahui isi dari pesan yang dikirimkan tersebut. Dengan adanya kriptografi, isi dari pesan akan diacak sedemikian rupa menggunakan algoritma kriptografi tertentu sehingga akan menghasilkan sebuah pesan yang acak yang tidak dapat dibaca sebelum isi pesan yang sebenarnya kembali dimunculkan menggunakan algoritma kriptografi tersebut. (Schneier, 1996)

\section{B. Enkripsi}

Merupakan hal yang sangat penting dalam kriptografi, merupakan pengamanan data yang dikirimkan agar terjaga kerahasiaannya. Pesan asli disebut plain text, yang diubah menjadi kode-kode yang tidak dimengerti. Enkripsi bisa diartikan dengan cipher atau kode. Sama halnya dengan jika tidak mengerti akan sebuah kata maka yang dilakukan adalah dengan melihatnya di dalam kamus atau daftar istilah. Beda halnya dengan enkripsi, untuk mengubah teks asli ke bentuk tekskode digunakan algoritma yang dapat mengkodekan data yang diinginkan

\section{Dekripsi}

Merupakan kebalikan dari enkripsi. Pesan yang telah dienkripsi dikembalikan ke bentuk asalnya (teks-asli), disebut dengan dekripsi pesan. Algoritma yang digunakan untuk dekripsi tentu berbeda atau kebalikan dengan algoritma yang digunakan untuk enkripsi

\section{Kunci \\ Kunci yang dimaksud di sini adalah kunci yang dipakai untuk melakukan enkripsi dan}

dekripsi. Kunci terbagi menjadi dua bagian, kunci rahasia (private key) dan kunci umum (public key). Maka pesan atau data asli sebelum dienkripsi disebut plain text. Sedangkan pesan yang sudah diacak disebut cipher text. Proses pengubahan plain text menjadi cipher text disebut dengan enkripsi, sedangkan proses pengubahan cipher text kembali menjadi plain text disebut dengan dekripsi.

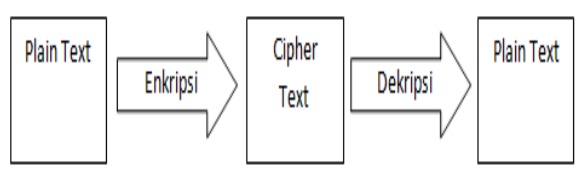

Gambar 1. Proses Enkripsi-Dekripsi

\section{E. Algoritma Blowfish}

Merupakan algoritma simetri yang tergolong dalam metode block cipher. Ada dua tipe dasar algoritma simetris yaitu block cipher dan stream cipher. Sebuah block cipher memproses block byte (biasanya 64 atau 128 bit ) pada satu waktu. Sebuah stream cipher memproses satu byte atau bahkan satu bit pada suatu waktu. (Thorsteinson and Ganesh, 2003)

Blowfish dibuat oleh seorang Cryptanalyst bernama Bruce Schneier, yang merupakan Presiden perusahaan Counterpane Internet Security.Inc, dan dipublikasikan tahun 1994. Algoritma ini digunakan pada komputer yang mempunyai microprocessor besar (32-bit keatas dengan cache data yang besar). (Schneier, 1996)

Karateristik Blowfish adalah sebagai berikut:

- Merupakan block cipher dengan 64 bit block

- Panjang kunci merupakan variable dengan panjang kunci hingga 448 bit

- Mengenkripsi data pada microprocessor 32 bit dengan rata - rata 18 clock cycle per byte, lebih cepat dari DES dan IDEA.

- Tidak mempunyai hak paten dengan harga yang gratis.

- Dapat berjalan pada memori kurang dari 5 KB.

- Mempunyai struktur yang sederhana dan implementasi yang mudah. (Pachghare, 2009)

Blowfish terdiri atas dua bagian :

1) Key-Expansion

Berfungsi merubah kunci (Minimum 32bit, Maksimum 448-bit) menjadi beberapa array subkunci (subkey) dengan total 4.168 byte.

2) Enkripsi Data

Terdiri dari iterasi fungsi sederhana (Feistel Network) sebanyak 16 kali putaran. Setiap putaran terdiri dari permutasi kunci dependent dan substitusi 
kunci dan data dependent. Semua operasi adalah penambahan (addition) dan XOR pada variabel 32-bit. Operasi tambahan lainnya hanyalah empat penelusuran tabel (table lookup) array berindeks untuk setiap putaran. (Schneier, 1996)

Blowfish menggunakan subkunci yang besar. Kunci tersebut harus dihitung sebelum enkripsi atau dekripsi data.

- Bentuk inisial P-array sebanyak 18 buah yaitu (P1,P2,...........P18) masingmsing bernilai 32-bit . P-array terdiri dari delapan belas kunci 32-bit subkunci: $\mathrm{P} 1, \mathrm{P} 2, \ldots \ldots ., \mathrm{P} 18$

- Bentuk S-Box sebanyak 4 buah masingmasing bernilai 32-bit yang memiliki masukan 256. Empat 32-bit S-Box masing-masing mempunyai 256 masukan:

$(\mathrm{S} 1,0),(\mathrm{S} 1,1)$, (S1,255)

$(\mathrm{S} 2,0),(\mathrm{S} 2,1)$

$(\mathrm{S} 3,0),(\mathrm{S} 3,1)$

$(\mathrm{S} 4,0),(\mathrm{S} 4,1)$

Blowfish adalah sebuah jaringan Feistel yang terdiri dari 16 putaran. Input-annya adalah elemen data 64 bit. Cara untuk melakukan enkripsi adalah sebagai berikut:

- Pertama-tama plain text yang akan dienkripsi diasumsikan sebagai masukan, plain text tersebut diambil sebanyak 64bit, dan apabila kurang dari 64-bit maka tambahkan bit nya, supaya dalam operasi nanti sesuai dengan datanya.

- Hasil pengambilan tadi dibagi 2, 32-bit pertama disebut XL, 32-bit yang kedua disebut XR.

- Selanjutnya lakukan operasi berikut:

For $\mathrm{i}=1$ to 16 ;

$\mathrm{XL}=\mathrm{XL}$ XOR Pi

$\mathrm{XR}=\mathrm{F}(\mathrm{XL}) \mathrm{XOR} \mathrm{XR}$

Tukar XL dan XR

- Setelah iterasi ke-16, tukar XL dan XR lagi untuk melakukan undo pertukaran terakhir. Lalu lakukan

XR $=$ XR XOR P17

$\mathrm{XL}=\mathrm{XL}$ XOR P1

Proses terakhir satukan kembali XL dan XR sehingga menjadi 64-bit kembali. (Scheiner, 1996).

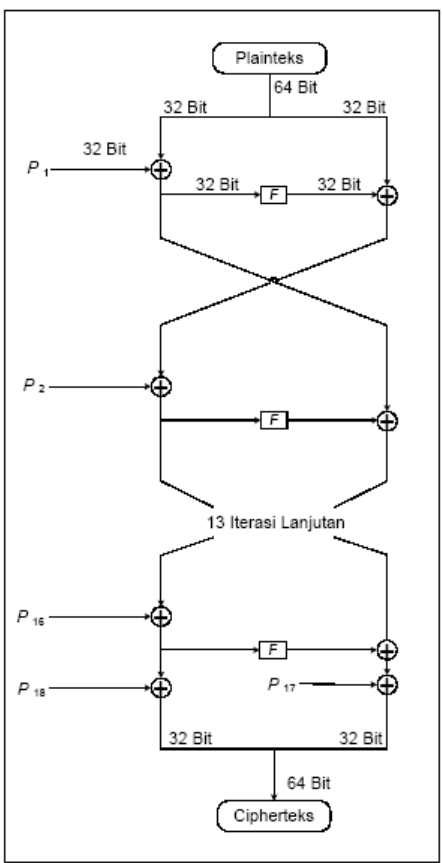

Gambar 2. Jaringan Feistel Algoritma Blowfish (Scheiner, 1996)

Fungsi $\mathrm{F}$ adalah sebagai berikut:

Bagi XL menjadi empat bagian 8-bit :

a,b,c dan d. $F(X L)=\left(\left(S_{1, a}+S_{2, b} \bmod 2^{32}\right)\right.$

$\left.X O R S_{3, c}\right)+S_{4, d} \bmod 2^{32}$.

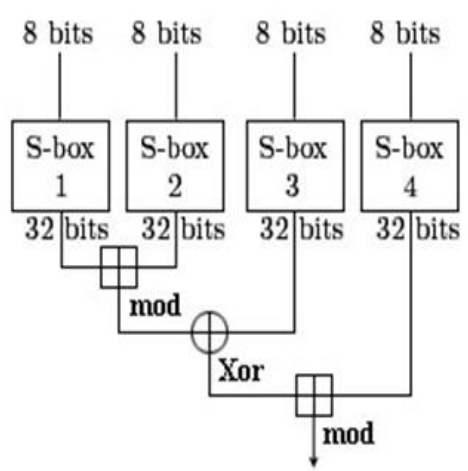

Gambar 3. Fungsi F Pada Algoritma Blowfish (Scheiner, 1996)

Cara untuk melakukan dekripsi sama dengan cara untuk melakukan enkripsi seperti diatas, namun pada proses dekripsi urutan P1, P2, .., P18 digunakan dalam urutan terbalik.

Subkunci dihitung menggunakan algoritma Blowfish, metodanya adalah sebagai berikut:

- Pertama-tama inisialisasi P-array dan kemudian empat $S$-Box secara berurutan dengan string yang tetap. String ini terdiri digit hexadesimal dari $\mathrm{p}$.

- $\quad$ XOR $\mathrm{P}_{1}$ dengan 32 bit pertama kunci, $X O R \mathrm{P}_{2}$ dengan 32 bit kedua dari kunci dan seterusnya untuk setiap bit dari kunci (sampai $\mathrm{P}_{18}$ ). Ulangi terhadap bit kunci sampai seluruh P-array di XOR dengan bit kunci. 
- Enkripsi semua string nol dengan algoritma Blowfish dengan menggunakan subkunci seperti dijelaskan pada langkah (1) dan (2).

- Ganti $\mathrm{P}_{1}$ dan $\mathrm{P}_{2}$ dengan keluaran dari langkah (3).

- Enkripsi keluaran dari langkah (3) dengan algoritma Blowfish dengan subkunci yang sudah dimodifikasi.

- Ganti $\mathrm{P}_{3}$ dan $\mathrm{P}_{4}$ dengan keluaran dari langkah (5).

- Lanjutkan proses tersebut, ganti seluruh elemen dari P-array, dan kemudian seluruh keempat $S$-Box berurutan, dengan keluaran yang berubah secara berlanjut dari algoritma Blowfish. (Scheiner, 1996)

\section{F. Algoritma Base64}

Transformasi Base64 merupakan salah satu algoritma untuk Encoding dan Decoding suatu data ke dalam format ASCII, yang didasarkan pada bilangan dasar 64 atau bisa dikatakan sebagai salah satu metoda yang digunakan untuk melakukan encoding (penyandian) terhadap data extension. Karakter yang dihasilkan pada transformasi Base64 ini terdiri dari A..Z, a..z dan 0..9, serta ditambah dengan dua karakter terakhir yang bersimbol yaitu + dan / serta satu buah karakter sama dengan (=) yang digunakan untuk penyesuaian dan menggenapkan data extension atau istilahnya disebut sebagai pengisi pad. Karakter simbol yang akan dihasilkan akan tergantung dari proses algoritma yang berjalan. Dalam Encoding Base64 dapat dikelompokkan dan dibedakan menjadi beberapa kriteria yang tertera

Tabel 1. Tabel indeks Base64

\begin{tabular}{|c|c|c|c|c|c|c|c|}
\hline $\begin{array}{c}\text { Data } \\
\text { 6bit }\end{array}$ & $\begin{array}{c}\text { Karakter } \\
\text { encoding 64 }\end{array}$ & $\begin{array}{c}\text { Data } \\
\text { 6bit }\end{array}$ & $\begin{array}{c}\text { Karakter } \\
\text { encoding 64 }\end{array}$ & $\begin{array}{c}\text { Data } \\
\text { 6 bit }\end{array}$ & $\begin{array}{c}\text { Karakter } \\
\text { encoding 64 }\end{array}$ & $\begin{array}{c}\text { Data } \\
\text { 6bit }\end{array}$ & $\begin{array}{c}\text { Karakter } \\
\text { encoding64 }\end{array}$ \\
\hline 0 & A & 16 & Q & 33 & l & 50 & y \\
\hline 1 & B & 17 & R & 34 & i & 51 & Z \\
\hline 2 & C & 18 & S & 35 & j & 52 & 0 \\
\hline 3 & D & 19 & T & 36 & k & 53 & 1 \\
\hline 4 & E & 20 & U & 37 & l & 54 & 2 \\
\hline 5 & F & 21 & V & 38 & m & 55 & 3 \\
\hline 6 & G & 22 & W & 39 & I & 56 & 4 \\
\hline 7 & H & 23 & X & 40 & 0 & 57 & 5 \\
\hline 8 & I & 24 & Y & 41 & P & 58 & 6 \\
\hline 9 & J & 25 & Z & 42 & q & 59 & 7 \\
\hline 10 & K & 26 & a & 43 & I & 60 & 8 \\
\hline 11 & L & 27 & b & 44 & S & 61 & 9 \\
\hline 12 & M & 28 & C & 45 & t & 62 & + \\
\hline 13 & N & 29 & d & 46 & U & 63 & I \\
\hline 14 & 0 & 30 & e & 47 & V & pad & $=$ \\
\hline 15 & P & 31 & f & 48 & W & & \\
\hline 16 & Q & 32 & g & 49 & X & & \\
\hline
\end{tabular}

Teknik encoding Base64 sebenarnya sederhana, jika ada satu (string) bytes yang akan disandikan ke Base64 maka caranya adalah sebagai berikut:

Misal kita ingin menyandikan teks MAN

- Ubah huruf - huruf yang akan di encripsi menjadi kode - kode ASCII

\begin{tabular}{|l||c||c||c||}
\hline Text content & M & a & n \\
\hline \hline ASCII & 77 & 97 & 110 \\
\hline
\end{tabular}

- Kode - kode ASCII tersebut ubah lagi menjadi kode Biner

\begin{tabular}{|c|c|c|c|}
\hline Text content & M & a & $n$ \\
\hline ASCII & 77 & 97 & 110 \\
\hline Bit pattern & $\begin{array}{lllll}0 & 1 & 0 & 0 & 1\end{array}$ & & 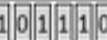 \\
\hline
\end{tabular}

- $\quad$ Bagi kode biner tersebut menjadi hanya 6 angka per blok dan berjumlah kelipatan 4 blok

- Jika angka biner tidak berjumlah 6 angka dan 4 blok maka akan di tambah kode biner 0 sehingga mencukupi menjadi 4 blok

- Blok - blok tsb ubah kembali menjadi kode desimal (data di baca sebagai index)

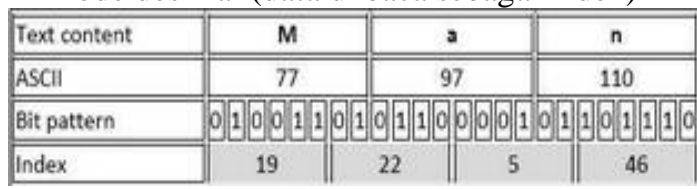

- Hasil kode index tersebut di ubah menjadi huruf yang ada pd index

\begin{tabular}{|c|c|c|c|c|}
\hline Text content & M & \multicolumn{2}{|r|}{ a } & $n$ \\
\hline ASCII & 77 & \multicolumn{2}{|r|}{97} & 110 \\
\hline Bit pattern & $\begin{array}{llllll}0 & 1 & 0 & 0 & 1 & 1\end{array}$ & $0[1]$ & 0 & 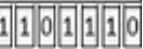 \\
\hline Index & 19 & 22 & 5 & 46 \\
\hline Base64-Encoded & T & W & $\mathbf{F}$ & $u$ \\
\hline
\end{tabular}

- Jika nilai blok adalah hasil tambahan (0) maka hasil dari index tersebut bernilai '='

\begin{tabular}{|c|c|c|c|c|}
\hline Text content & M & & & \\
\hline ASCII & 77 & & & \\
\hline Bit pattern & 100.1 & & & (Maly \\
\hline Index & 19 & 16 & (kosong) & (kosong) \\
\hline Base64-Encoded & $T$ & a & " & " \\
\hline
\end{tabular}

\section{ANALISA MASALAH DAN RANCANGAN SISTEM}

\section{A. Analisa Masalah}

Pengamanan data pada suatu instansi pemerintah merupakan hal yang sangat penting dan vital mengingat data tersebut tidak boleh diketahui oleh masyarakat umum data pada dinas kependudukan dan pencatatan sipil seperti data catatan sipil yaitu data kematian, data kelahiran dan data pernikahan. Untuk mengatasi data tersebut agar tidak diketahui oleh masyarakat umum maka diperlukan suatu aplikasi yang dapat menyandikan 
atau mengenkripsi data tersebut, penulis ingin membuat aplikasi pengamanan data pada Dinas Kependudukan dan Pencatatan Sipil menggunakan Algoritma Blowfish dan Base64. Dimana mekanismenya nanti data-data tersebut discan terlebih dahulu kemudian file image hasil scanan akan di enkripsi menggunakan algoritma blowfish terlebih dahulu baru kemudian di enkripsi lagi dengan algoritma Base64 kemudian baru disimpan kedalam basis data, jika kita ingin melihat data hasil enkripsi menjadi data asli maka kita mendekrip data tersebut. Jika digambarkan dalam bentuk Rich Picture sebagai berikut:

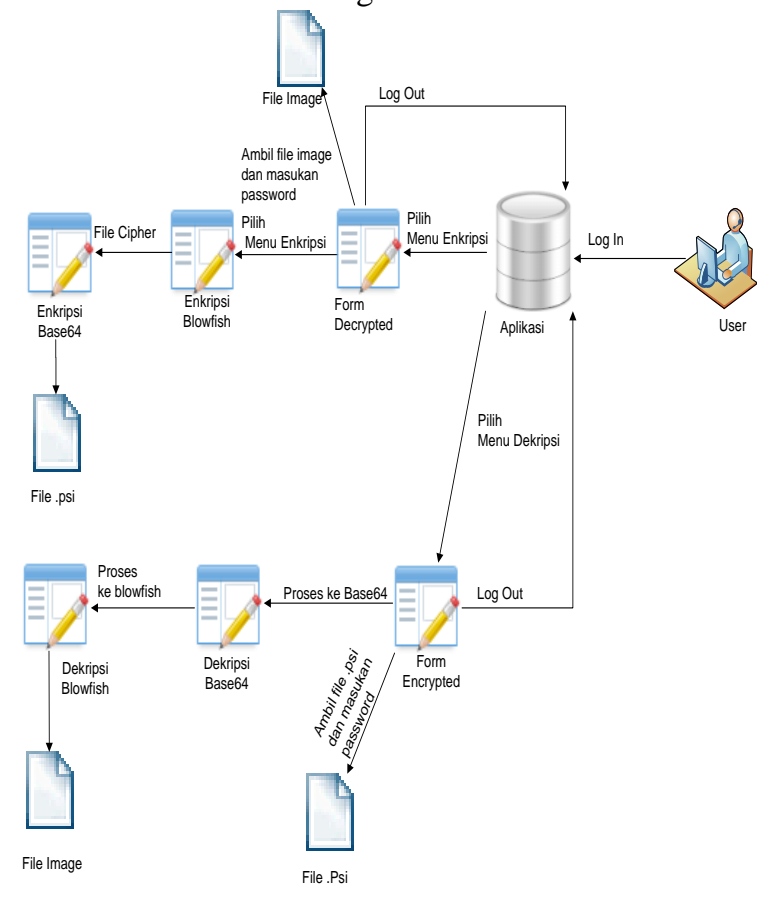

Gambar 4. Rich Picture Aplikasi

B. Activity Diagram

Activity Diagram digunakan untuk menjelaskan proses kegiatan yang terjadi pada program.

Berikut adalah Activity Diagram pada proses enkripsi Blowfish:

1) Activity Diagram Enkripsi Blowfish

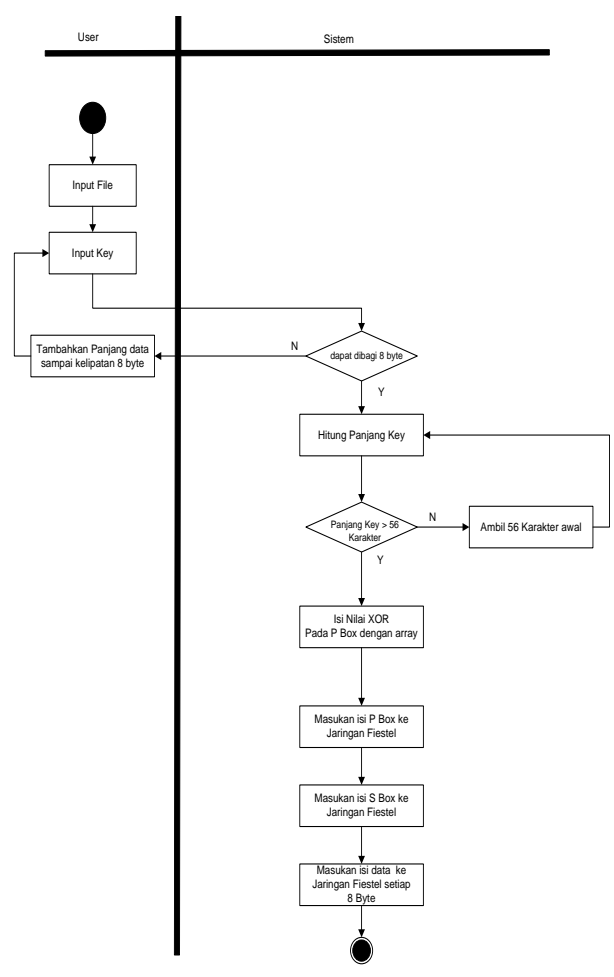

Gambar 5. Tampilan Activity Diagram Blowfish

2) Activity Diagram Enkripsi Base64

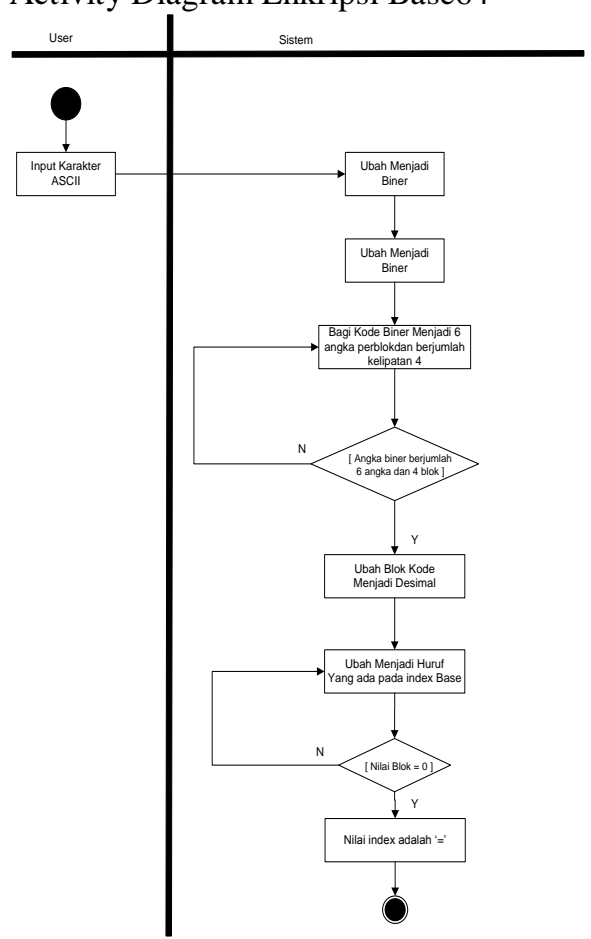

Gambar 6. Tampilan Activity Diagram Base64 


\section{Use Case Diagram}

Use case diagram menjelaskan bagaimana seorang user dalam menjalankan aplikasi enkrpsi dan dekripsi

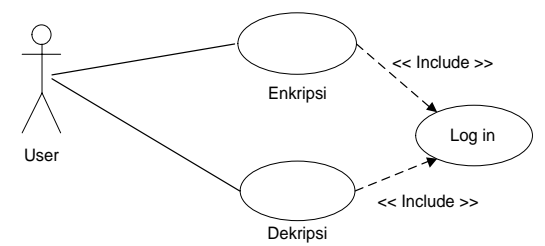

Gambar 7. Use Case Diagram

\section{State Diagram}

State diagram digunakan untuk mendeskripsi kan perilaku sistem. State diagram mendeskripsi kan semua kondisi yang mungkin muncul sebagai sebuah object begitu pula dengan event.

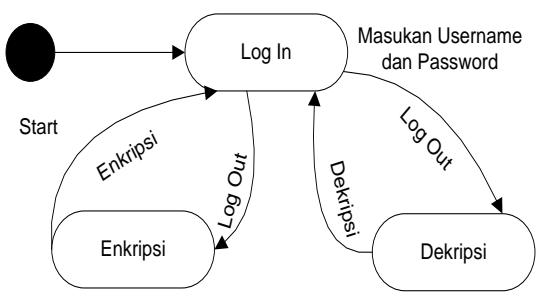

Gambar 8. State Diagram

Program start kemudian Login dan akan tampil pilihan menu Enkripsi dan Dekripsi dan pada menu enkripsi dan dekripsi terdapat fungsi $\log$ out

\section{IMPLEMENTASI DAN ANALISA PROGRAM}

Dalam melakukan uji coba untuk mengetahui hasil dari proses enkripsi dan dekripsi tersebut, maka kebutuhan komputer yang harus dipenuhi adalah sebagai berikut.

\section{A. Tampilan Layar Form Log in}

User yang akan menggunakan aplikasi enkripsi harus log in terlebih dahulu.

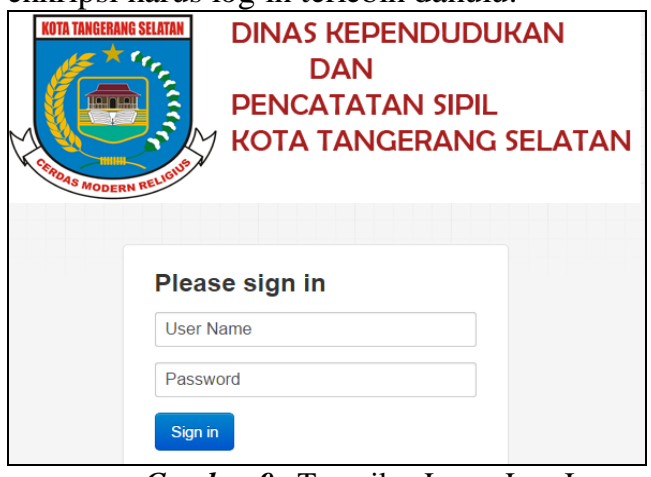

Gambar 9. Tampilan Layar Log In

\section{B. Tampilan Layar Form Enkripsi}

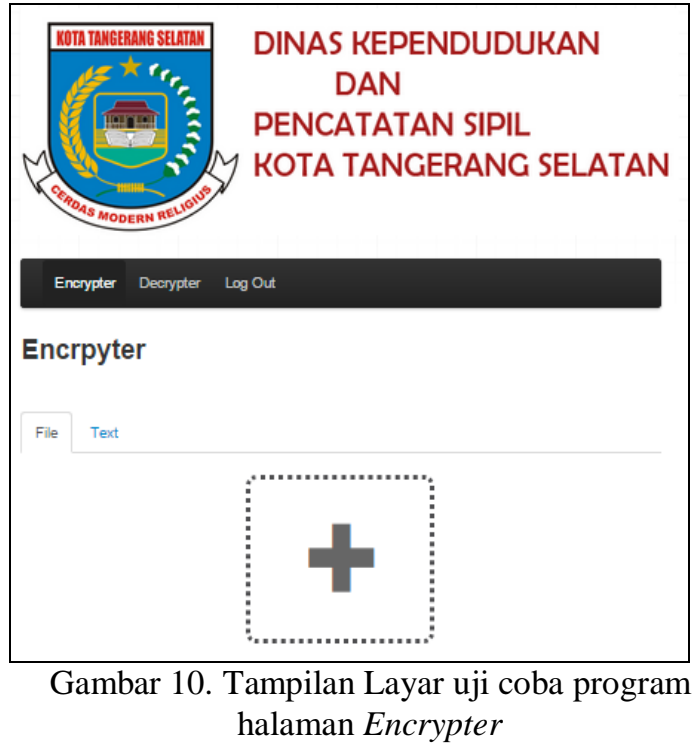

A. Kesimpulan

\section{KESIMPULAN}

Berdasarkan hasil penelitian dan pembahasan serta uji coba sistem dapat disimpulkan sebagai berikut :

- Data dapat diamankan dengan kriptografi algortima Blowfish dan Base64.

- Data tidak dapat dibuka oleh pihak yang tidak berhak yang tidak memiliki kunci untuk enkripsi dan dekripsi file.

- File yang diamankan menggunakan aplikasi ini tidak dapat dibuka oleh aplikasi lain.

- Program sistem keamanan dengan sistem kriptografi algoritma Blowfish dan Base64 telah diuji coba, sehingga program dinyatakan sudah sesuai.

\section{B. Saran}

Pengembangan yang perlu dilakukan untuk penelitian berikutnya adalah sebagai berikut:

- Aplikasi ini mengenkripsi dan mendekripsi file image dan beberapa file menggunakan algoritma Blowfish dan base64 untuk itu bisa di gunakan dengan algoritma yang berbeda yang menggunakan kunci public seperti RSA.

- Ukuran file yang dihasilkan dapat diperkecil dengan menerapkan proses kompresi data.

\section{DAFTAR PUSTAKA}

[1] Adriansyah, Yusuf. 2010. Enkripsi Sederhana dengan Base64 dan Subtitusi Monoalfabetik ke Huruf Non-Latin. Makalah Mahasiwa Teknologi Bandung. 
[2] Ariyus, Dony., 2008 Pengantar Ilmu Kriptografi Teori, Analisis, dan Implementasi, Andi Offset, Yogyakarta.

[ 3 ] Hendarsyah, Decky\& Wardoyo,Retantyo (2012) Implementasi Protokol Diffie Hellman Dan Algoritma RC4 Untuk Keamanan Pesan SMS. Universitas Gajah Mada

[ 4 ] Kurniawan, J., 2004, Kriptografi, Keamanan Internet dan Jaringan Komunikasi, Informatika Bandung.

[ 5 ] Schneier, B., 1996, Applied Crytography: Protocols, Algorithm, and Source Code in $C$, Second Edition, John Willey and Sons Inc.

[ 6] Thorsteinson, Peter dan G. Gnana Arun Ganesh, 2004, .NET SECURITY and CRYPTOGRAPHY.USA : Pearson Education, Inc

[ 7 ] Borenstein, N. \& N. Freed, 1996. Multipurpose Internet Mail Extensions (MIME) Part One : Format of Internet Message Bodies. RFC 2045. Network Working Group

[ 8 ] Suriski Sitinjak, Fauziah, Yuli Juwairiah, "APLIKASI KRIPTOGRAFI FILE MENGGUNAKAN BLOWFISH", Seminar Nasional Informatika, 2010

[9] Ahmad Timbul Sholeh, Erwin Gunadhi, Asep Deddy Supriatna, "MENGAMANKAN SKRIP PADA BAHASA PEMOGRAMAN PHP
DENGAN

MENGGUNAKAN

KRIPTOGRAFI BASE64", 2013

[10] Reza Fitra Kesuma "PEMBUATAN PERANGKAT LUNAK SEBAGAI MEDIA PEMBELAJARAN KRIPTOGRAFI MODERN METODE BLOWFISH", Naskah Publikas, 2013

[11] Andy Nugroho "IMPLEMENTASI ALGORIMA CAESAR CIPHER ROT13 DAN BASE64 UNTUK ENKRIPSI DAN DESKRIPSI PESAN SMS PADA HANDPHONE BERBASIS ANDROID", Naskah Publikasi, 2012

[ 12] Ari Suhendra "ANALISIS DAN IMPLEMENTASI ENKRIPSI BASIS DATA DENGAN ALGORITMA KRIPTOGRAFI BLOWFISH", Naskah Publikasi, 2012

[13] Shanty Erikawaty Tambunan "IMPLEMENTASI ALGORITMA KRIPTOGRAFI BLOWFISH UNTUK KEAMANAN DOKUMEN PADA MICROSOFT OFFICE”, Naskah Publikasi, 2010

[ 14 ] http://sinta.ukdw.ac.id, IMPLEMENTASI ALGORITMA KRIPTOGRAFI BLOWFISH UNTUK ENKRIPSIDEKRIPSI CITRA DIGITAL KE DALAM BENTUK TEKS, di akses tanggal 19 Juni 2015 